\title{
Flutuação populacional e distribuição de Sitophilus zeamais em pomares de pessegueiro e macieira
}

\author{
Sandro Daniel Nörnberg(1), Dori Edson Nava(2), Anderson Dionei Grützmacher ${ }^{(1)}$, José Maurício Simões Bento(3), \\ Ângelo Luis Ozelame ${ }^{(1)}$ e Lucas Kuhn Hübner ${ }^{(1)}$ \\ (1)Universidade Federal de Pelotas, Faculdade de Agronomia Eliseu Maciel, Departamento de Fitossanidade, Caixa Postal 354, \\ CEP 96010-900 Pelotas, RS. E-mail: sandro_ufpel@hotmail.com, anderson.grutzmacher@pq.cnpq.br, angeloluisozelame@hotmail.com, \\ lucas.hubner@yahoo.com.br (2)Embrapa Clima Temperado, Laboratório de Entomologia, BR 392, Km78, Caixa Postal 403, CEP 96001-970 \\ Pelotas, RS. E-mail: dori.edson-nava@embrapa.br (3)Universidade de São Paulo, Escola Superior de Agricultura Luiz de Queiroz, \\ Departamento de Entomologia e Acarologia, Laboratório de Ecologia Química e Comportamento de Insetos, Avenida Pádua Dias, no 11, \\ CEP 13418-900 Piracicaba, SP. E-mail: jmsbento@usp.br
}

Resumo - O objetivo deste trabalho foi avaliar a flutuação populacional de Sitophilus zeamais (Coleoptera: Curculionidae) e determinar a distribuição deste inseto-praga nas plantas de pessegueiro e macieira na região de Pelotas, no Rio Grande do Sul. A flutuação populacional foi avaliada nas safras 2009/2010 e 2010/2011, por meio de monitoramento semanal com armadilhas dos pomares, durante aproximadamente cinco meses. Foram usadas dez armadilhas do tipo Pet-milho por hectare, posicionadas a 1,7 $\mathrm{m}$ do solo, distribuídas de maneira equidistante nas bordas e no centro do pomar. A distribuição do inseto nas plantas foi avaliada nos frutos dos terços superior, mediano e inferior das plantas, na cultivar de maçã Eva e nas cultivares de pêssego Sensação (ciclo precoce), Eldorado (ciclo tardio) e Eragil (ciclo tardio). Em macieira, o ataque de S. zeamais ocorreu por cinco a sete semanas, e, em pessegueiro, por três a quatro semanas. Foi observado maior número de $S$. zeamais machos no início da infestação dos pomares, principalmente nos frutos do terço superior das plantas. Nas semanas seguintes, a maior infestação de frutos se deu no terço médio. O ataque de Sitophilus zeamais ocorre tanto em cultivares precoces como em tardias de pessegueiro, com pico de ataque no período de colheita.

Termos para indexação: Malus domestica, Prunus persica, época de controle, gorgulho-do-milho, monitoramento.

\section{Population dynamics and distribution of Sitophilus zeamais in peach and apple orchards}

\begin{abstract}
The objective of this work was to evaluate the population dynamics of Sitophilus zeamais (Coleoptera: Curculionidae) and to determine the distribution of this pest in plants of peach and apple orchards, in the region of Pelotas, state of Rio Grande do Sul, Brazil. Population dynamics was evaluated in the 2009/2010 and 2010/2011 growing seasons by weekly monitoring the orchards with traps for approximately five months. Ten "Pet-milho"-type traps were used per hectare, positioned $1.7 \mathrm{~m}$ above the ground, distributed equidistantly in the borders and in the center of the orchards. Insect distribution in plants was evaluated in fruits from the top, middle, and bottom portions of the plants, in the apple cultivar Eva and in the peach cultivars Sensação (early cycle), Eldorado (late cycle), and Eragil (late cycle). In apple, S. zeamais attack occurred for five to seven weeks, and in peach, for three to four weeks. A greater number of S. zeamais males was observed at the beginning of the orchard infestation, mainly in fruits from the top portion of the plants. In the following weeks, the highest infestation of fruits occurred in the middle portion. Sitophilus zeamais attack occurs both in early and late cultivars of peach, with a peak attack at the harvesting stage.
\end{abstract}

Index terms: Malus domestica, Prunus persica, control timing, maize weevil, monitoring.

\section{Introdução}

A produção de frutas de clima temperado, como o pêssego [Prunus persica (L.) Batsch] e a maçã (Malus domestica Borkh), tem crescido no Brasil. Mudanças nos sistemas de produção têm acompanhado esse crescimento, com o objetivo de atender às exigências do mercado consumidor brasileiro e superar as barreiras fitossanitárias impostas por países importadores (Fachinello et al., 2011).

A mosca-das-frutas sul-americana, Anastrepha fraterculus (Wiedemann, 1830) (Diptera: Tephritidae), e a mariposa-oriental, Grapholita molesta (Busck, 1830) (Lepidoptera: Tortricidae) são exemplos de 
espécies de inseto-praga comuns às culturas do pessegueiro e da macieira (Arioli et al., 2004; Nava \& Botton, 2010). O manejo destes insetos abrange sistemas de monitoramento e controle integrado definidos, em uso pelos fruticultores (Härter et al., 2010; Nava \& Botton, 2010).

Artrópodes-praga de importância secundária podem adquirir status de praga-chave com a redução da diversidade biológica dos agroecossistemas, decorrente do monocultivo e do manejo fitossanitário não seletivo. Além disso, insetos-praga de um tipo de cultivo podem tornar-se praga em outro. Neste contexto, destaca-se o gorgulho-do-milho, Sitophilus zeamais Motschulsky, 1855 (Coleoptera: Curculionidae), um inseto-praga típico de grãos armazenados que tem causado danos em frutas de clima temperado, com relatos de ocorrência em pêssego, ameixa, marmelo, maçã e uva (Salles, 2003; Botton et al., 2005b; Hickel \& Schuck, 2005).

Na região de Pelotas, RS, que responde pela maior área de beneficiamento e armazenamento de arroz do Brasil (Elias et al., 2012), a espécie Sitophilus oryzae (Linnaeus, 1763) (Coleoptera: Curculionidae) infesta os locais de armazenamento do grão e pode migrar para os pomares de pessegueiro. Tradicionalmente conhecida como produtora de pêssegos para indústria, esta região dispõe de cultivares com início de colheita entre outubro-novembro até meados de fevereiro, com ciclos precoce, médio e tardio (Raseira \& Nakasu, 2006). Esses diferentes ciclos de maturação possibilitam exposição de frutos ao ataque de $S$. zeamais durante um período considerável de tempo; contudo, não são conhecidos trabalhos que tenham mostrado esta ocorrência ou que comprovem que o ataque do gorgulho-do-milho seja restrito ao período de colheita nas frutíferas de diferentes ciclos de maturação. Além disso, uma das características das pequenas propriedades rurais é a diversificação da matriz produtiva, em que é possível encontrar, não apenas pessegueiro, mas outras frutíferas, como a macieira.

Na cultura do pessegueiro, o ataque de $S$. zeamais, em cultivares de ciclo tardio, ocorre no momento da colheita (na primeira coleta de frutos), nos meses com temperaturas mais altas (Salles, 2003); nessa época, também se concentra a colheita de maçã, a qual tem sido introduzida como cultura alternativa por persicultores.

O controle de $S$. zeamais em pomares com a utilização de inseticidas, único método atualmente disponível, pode representar um risco, já que a aplicação de produtos químicos na fase de colheita pode ocasionar problemas de resíduos nos frutos (Lima et al., 2009) e comprometer o sistema de produção integrada de frutas (Silva et al., 2011). Neste sentido, torna-se imprescindível determinar o momento em que os gorgulhos infestam os pomares para estabelecer a melhor época para a adoção de controle.

O objetivo deste trabalho foi avaliar a flutuação populacional de S. zeamais e determinar a distribuição deste inseto-praga nas plantas de pessegueiro e macieira, na região de Pelotas, Rio Grande do Sul.

\section{Material e Métodos}

Os experimentos foram realizados em duas safras agrícolas, 2009/2010 e 2010/2011, em três pomares comerciais de pessegueiro ('Sensação', 'Eldorado' e 'Eragil') e um de macieira ('Eva'), localizados no Município de Pelotas, RS ( $31^{\circ} 37^{\prime} 23^{\prime \prime S}$ e $52^{\circ} 36^{\prime} 16^{\prime \prime} \mathrm{W}$, a $175 \mathrm{~m}$ de altitude). O clima da região é do tipo Cfa, segundo a classificação de Köppen: temperado úmido, com verões quentes. Foram registradas médias anuais de temperatura e precipitação de $17,9^{\circ} \mathrm{C}$ e $1.500 \mathrm{~mm}$, respectivamente. As práticas de manejo cultural e fitossanitário nos pomares seguiram as indicações técnicas para cada cultura.

Em cada pomar, foram delimitadas áreas experimentais de aproximadamente $1 \mathrm{ha}$, as quais foram divididas em cinco subáreas para disposição de armadilhas e seleção das plantas. Foram instaladas duas armadilhas e selecionadas duas plantas em cada subárea, o que totalizou dez armadilhas e dez plantas para avaliação dos frutos, em cada pomar.

Para a avaliação da flutuação populacional de adultos de $S$. zeamais, durante as duas safras, foram utilizadas armadilhas adaptadas do tipo Pet-milho, conforme recomendação para a cultura da videira (Hickel \& Schuck, 2008), tendo-se utilizado, como atrativo alimentar, aproximadamente $100 \mathrm{~g}$ de grãos de milho. As armadilhas foram distribuídas de maneira equidistante nas bordas e no centro do pomar, posicionadas nas plantas a 1,7 $\mathrm{m}$ do solo. Paralelamente, realizou-se a avaliação de 20 frutos por planta, o que totalizou 200 frutos por semana em cada pomar.

As avaliações foram realizadas semanalmente, durante um período de 19 semanas, por meio da contagem dos gorgulhos capturados nas armadilhas e 
da observação da ocorrência de danos causados pelos gorgulhos nos frutos.

Os insetos amostrados durante o monitoramento foram armazenados em álcool a $70 \%$ e encaminhados para posterior identificação, a qual foi realizada com base na classificação proposta por Bouchard et al. (2011).

A distribuição do ataque de $S$. zeamais nas plantas foi determinada na safra 2010/2011, na cultivar de pessegueiro Eldorado (com histórico de ataque na área estudada) e na cultivar de macieira Eva (única cultivada na região de estudo). No momento em que foi registrada a primeira captura de gorgulhos em armadilhas ou a sua ocorrência em frutos, dez plantas foram selecionadas ao acaso, por área experimental, as quais foram avaliadas quanto ao número de frutos atacados por $S$. zeamais em três alturas das plantas: até $1 \mathrm{~m}$ de altura a partir do solo (terço inferior), entre 1,0 e $1,70 \mathrm{~m}$ (terço médio) e acima de $1,70 \mathrm{~m}$ (terço superior). Em cada altura, observou-se o número de gorgulhos por fruto e realizou-se a coleta dos gorgulhos para avaliar a razão sexual por meio da dissecação em laboratório.

A flutuação populacional de adultos de $S$. zeamais, em cada pomar, foi obtida em cada ano a partir do número de gorgulhos capturados por semana em função do tempo. Os dados referentes à distribuição de frutos atacados nas plantas foram testados quanto à normalidade e à homocedasticidade e submetidos à análise de variância; as médias foram comparadas pelo teste de Tukey, a 5\% de probabilidade (SAS Institute, 2002).

\section{Resultados e Discussão}

Todos os gorgulhos coletados nas áreas experimentais, durante as duas safras, foram identificados como da espécie S. zeamais. A ocorrência desta espécie já havia sido relatada em frutas de caroço, como pêssego, ameixa, nectarina, maçã e uva (Salles, 2003; Botton et al., 2005a, 2005b; Hickel \& Schuck, 2005), e está relacionada a falhas no armazenamento do milho (Salles, 2003; Botton et al., 2005b), que é o cereal mais cultivado em pequenas propriedades rurais nas regiões produtoras de pêssego. A maior atividade de voo de $S$. zeamais em comparação a S. oryzae (Vásquez-Castro et al., 2009) também pode ser determinante para a migração e a ocorrência da espécie em pomares de pessegueiro e macieira.
Nos pomares de pessegueiro, a infestação de S. zeamais iniciou-se de uma a duas semanas antes do pico de colheita (Figuras 1 e 2), e estendeu-se por três a quatro semanas, independentemente do ano de avaliação e do ciclo de produção. Na macieira, pelo fato de o período de maturação dos frutos ser maior, a ocorrência de $S$. zeamais se deu por um período de sete semanas, nos dois anos avaliados. Nesta espécie, o início da infestação ocorreu de três a quatro semanas antes do pico de colheita, indício de que o ataque em maçã pode ocorrer com a maioria dos frutos ainda verde, diferentemente do que ocorre em pêssego, em que o ataque concentra-se em épocas em que predominam frutos maduros.
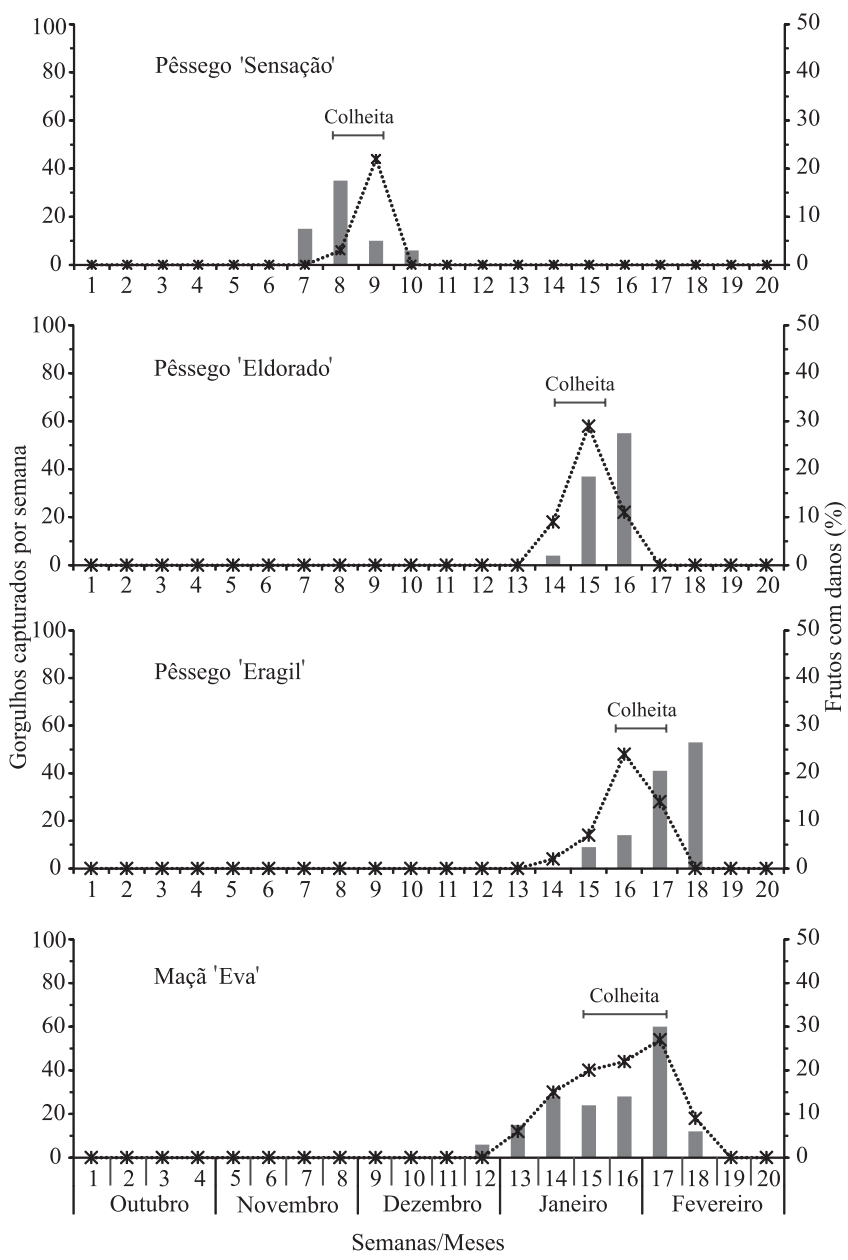

Figura 1. Número de gorgulhos capturados em armadilhas Pet-milho (barras) e percentagem de danos (linha) por Sitophilus zeamais em frutos de pessegueiro, cultivares Sensação, Eldorado e Eragil, e de macieira, cultivar Eva, na safra 2009/2010. 
$\mathrm{Na}$ cultivar de ciclo precoce Sensação, a captura de gorgulhos em armadilhas foi menor, com pico máximo de 38 gorgulhos, na safra 2009/2010 (Figura 1), e de 23 gorgulhos na safra 2010/2011 (Figura 2). A percentagem de frutos danificados por ocasião da colheita foi menor que $5 \%$. A colheita dessa cultivar ocorreu em novembro, nos dois anos de estudo, o que mostra que, mesmo em temperaturas mais baixas, $S$. zeamais pode migrar para os pomares.

A maior quantidade de gorgulhos foi capturada na cultivar Eldorado, de ciclo tardio, com período de colheita entre final de dezembro e início de janeiro, em que foram observados picos de 55 gorgulhos, na safra

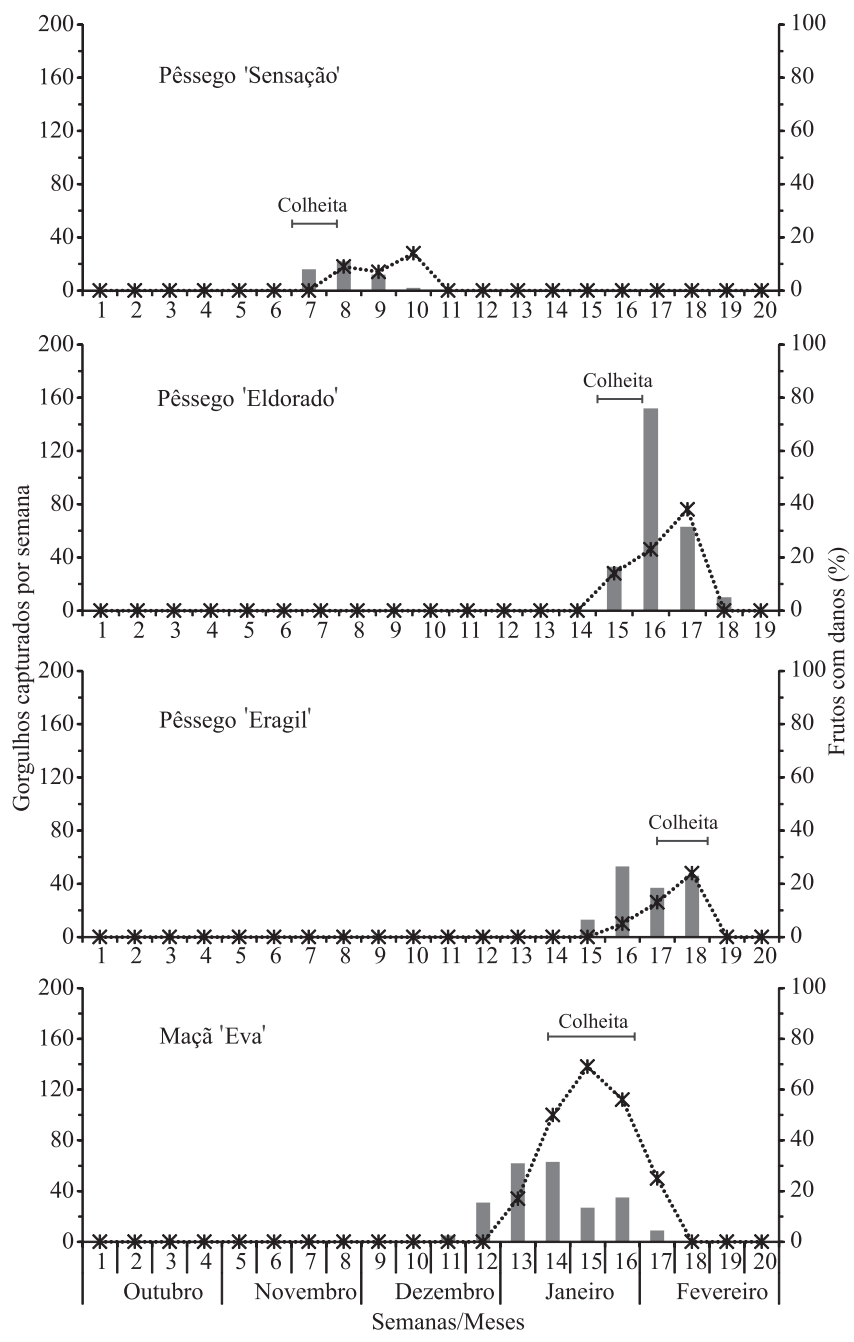

Figura 2. Número de gorgulhos capturados em armadilhas Pet-milho (barras) e percentagem de danos (linha) por Sitophilus zeamais em frutos de pessegueiro, cultivares Sensação, Eldorado e Eragil, e de macieira, cultivar Eva, na safra 2010/2011.
2009/2010 (Figura 1), e de 142 gorgulhos na safra 2010/2011 (Figura 2). A média de frutos com danos no início da colheita foi de $28 \%$ em 2009/2010 e de $38 \%$ em 2010/2011.

$\mathrm{Na}$ cultivar Eragil, de ciclo tardio, a captura apresentou picos máximos de 51 gorgulhos, na safra 2009/2010 (Figura 1), e de 54 gorgulhos na safra 2010/2011 (Figura 2). A média de frutos com danos foi de $24 \%$ em 2009/2010 e de $26 \%$ em 2010/2011.

$\mathrm{Na}$ cultura da macieira, foi registrado pico de captura de 60 gorgulhos no primeiro ano (2009/2010) (Figura 1), logo após o pico de colheita. No segundo ano (2010/2011), foram observados dois picos consecutivos de captura, de 63 e 62 gorgulhos, anteriores ao pico de colheita. Dessa forma, foi observada elevada infestação dos frutos no segundo ano de estudo (2010/2011), em que, no momento da colheita, mais de $60 \%$ apresentavam danos ocasionados pelo gorgulho, comumente na região de contato entre frutos e pedúnculo. Foram observados, em média, seis gorgulhos por fruta, índice superior ao normalmente encontrado em pêssego, que é de dois a quatro gorgulhos por fruta (Salles, 2003).

A preferência de $S$. zeamais por frutos maduros fica evidente nos dois anos de avaliação, tanto em pessegueiro como em macieira. Essa preferência pode ser resultante de diversos fatores, bióticos ou abióticos, como condições climáticas, características físico-químicas dos frutos e bioecologia do inseto.

As condições meteorológicas são importantes para a bioecologia deste inseto-praga (Likhayo \& Hodges, 2000); no entanto, provavelmente, elas não são o fator condicionante ao ataque em frutíferas, já que este ocorreu tanto em cultivar precoce (Sensação), com temperatura média menor, como em cultivares tardias (Eldorado e Sensação) (Figuras 1 e 2).

Portanto, fatores relacionados aos frutos, como composição química e características físicas, devem constituir possíveis condicionantes ao ataque, pois, independentemente do ciclo de produção, ele se concentrou em frutos maduros (Figuras 1 e 2). A cor é uma característica física utilizada pelos gorgulhos para orientação quanto a possíveis abrigos ou substratos alimentares (Hickel \& Schuck, 2008). Em pêssego e maçã, ocorre a modificação da coloração durante o processo de maturação, que passa da cor verde para o amarelo ou o vermelho (Toralles et al., 2008).

Pesq. agropec. bras., Brasília, v.48, n.4, p.358-364, abr. 2013 DOI: 10.1590/S0100-204X2013000400002 
Entre os compostos químicos das frutas, os fenóis constituem um grupo de metabólitos secundários que exercem papel importante nas plantas, principalmente como proteção a fatores bióticos e abióticos. Esses compostos podem atuar como inibidores digestivos a insetos-praga, ou como produtores de radicais livres (Appel, 1993). Isso pode ser outro fator a condicionar o ataque de $S$. zeamais preferencialmente em frutos maduros, já que, neste estádio, as concentrações destes compostos tendem a ser menores.

$\mathrm{O}$ ataque mais intenso observado a partir de janeiro nas cultivares de pessegueiro de ciclo tardio e na cultivar de macieira (Figuras 1 e 2) também pode ser explicado, em parte, pelo comportamento de $S$. zeamais na região de estudo. Isso porque a espécie tende a migrar dos paióis (ou locais de armazenamento de grãos de milho) em busca de uma fonte alimentar alternativa, em razão da superpopulação de gorgulhos no milho armazenado (Salles, 2003; Botton et al., 2005b). Neste contexto, fica claro que o manejo deste inseto-praga deve ser integrado, a começar do armazenamento de grãos, para reduzir a migração aos pomares.

$\mathrm{O}$ ataque de $S$. zeamais em pessegueiro 'Eldorado' e na macieira 'Eva' iniciou-se no terço superior das plantas, a uma altura maior que 1,7 m (Figura 3). Na primeira semana em que foi detectada a presença de gorgulhos nos pomares, cerca de $75 \%$ dos frutos atacados nessas plantas encontravam-se no terço superior (Figura 3). A informação quanto à porção da planta em que se inicia o ataque é importante para o estabelecimento de um sistema de monitoramento de insetos-praga em pomares. Nas semanas subsequentes, a maior proporção de frutos atacados foi detectada na região mediana da planta. Em pêssego, esta proporção foi maior a partir da segunda semana após a detecção do inseto no pomar e, na macieira, a partir da terceira avaliação (Figura 3).

$\mathrm{Na}$ macieira, não houve diferença significativa quanto à percentagem total de frutos com danos entre o terço superior $(>1,7 \mathrm{~m})$ e o médio das plantas (entre 1,0 e 1,7 m). Já para o pessegueiro, verificou-se maior proporção de frutos com dano no terço médio (entre 1,0 e 1,7 m), que diferiu significativamente da quantidade de frutos com dano nos terços superior e inferior $(<1,0 \mathrm{~m})$ (Figura 3).

$\mathrm{Na}$ safra 2010/2011, durante o período de ataque de S. zeamais em pêssego 'Eldorado' e maçã 'Eva', observou-se que, no início da infestação (primeira semana com ataque), os primeiros insetos a chegarem aos pomares foram predominantemente machos e que a razão sexual dos insetos foi baixa: 0,10 , em pêssego, e 0,15 em maçã. No decorrer deste período, houve aumento na percentagem de frutos atacados (Figura 2), provavelmente ocasionado pelo aumento no número de gorgulhos no pomar, constatado pelo número de gorgulhos capturados nas armadilhas (Figura 2). Também houve aumento na proporção de fêmeas, tendo-se obtido razão sexual de 0,5 no total de insetos coletados (Figura 4).

$\mathrm{O}$ fato de os primeiros gorgulhos encontrados nos pomares serem predominantemente machos (Figura 4) pode ser atribuído ao comportamento típico de insetos que se utilizam do feromônio de agregação, em que os machos migram em busca de um substrato adequado para alimentação e reprodução e, ao encontra-lo, liberam o feromônio de agregação para atração dos coespecíficos (Moreira et al., 2005).

A presença de voláteis de macieira tem impacto significativo sobre a resposta do gorgulho-da-ameixa Conotrachelus nenuphar (Herbst, 1797) (Coleoptera: Curculionidae) em armadilhas de monitoramento. Esses compostos, emitidos principalmente após a

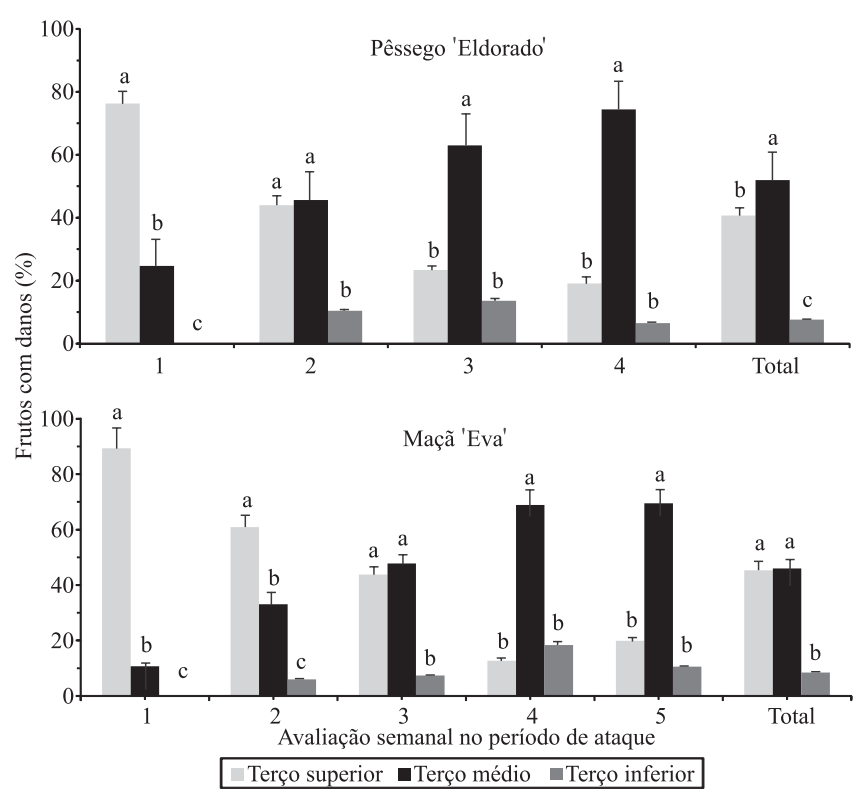

Figura 3. Distribuição de frutos danificados por Sitophilus zeamais em plantas de pessegueiro, cultivar Eldorado, e de macieira, cultivar Eva, durante o período de ataque. Barras indicadas por letras iguais, na comparação entre as alturas de avaliação, não diferem pelo teste de Tukey, a 5\% de probabilidade. 
formação dos frutos, são mais atrativos do que a utilização isolada do feromônio (Leskey \& Wright, 2004). Nos gorgulhos, esse comportamento foi observado para S. oryzae, que só libera seu feromônio de agregação na presença do substrato alimentar (Landolt \& Phillips, 1997). Além disso, estudos conduzidos em laboratório têm mostrado que voláteis emitidos por grãos hospedeiros são atrativos a $S$. zeamais (Ukeh et al., 2010). Neste contexto, é possível que o mesmo comportamento ocorra na interação entre $S$. zeamais e os frutos de pessegueiro e macieira, em que os voláteis emitidos pelos frutos são mediadores dessa interação e também são os responsáveis pela atratividade dos frutos maduros a $S$. zeamais.

O monitoramento de $S$. zeamais em pomares de pessegueiro e macieira com a utilização de armadilhas do tipo Pet-milho pode ser considerado eficaz, já que, embora elas tenham sido instaladas a uma altura de 1,70 m, ainda foi possível detectar o início de ataque, independentemente da cultivar avaliada (Figuras 1 e 2).

Contudo, apesar das dez armadilhas dispostas numa área aproximada de 1 ha, observou-se grande quantidade de gorgulhos nos frutos, o que evidencia que as armadilhas com iscas não têm função de controlar ou impedir o ataque da praga. Além disso, seriam necessários estudos para identificar substratos mais atrativos aos gorgulhos, uma vez que, atualmente, não se dispõe, no mercado, de armadilhas ou atrativos

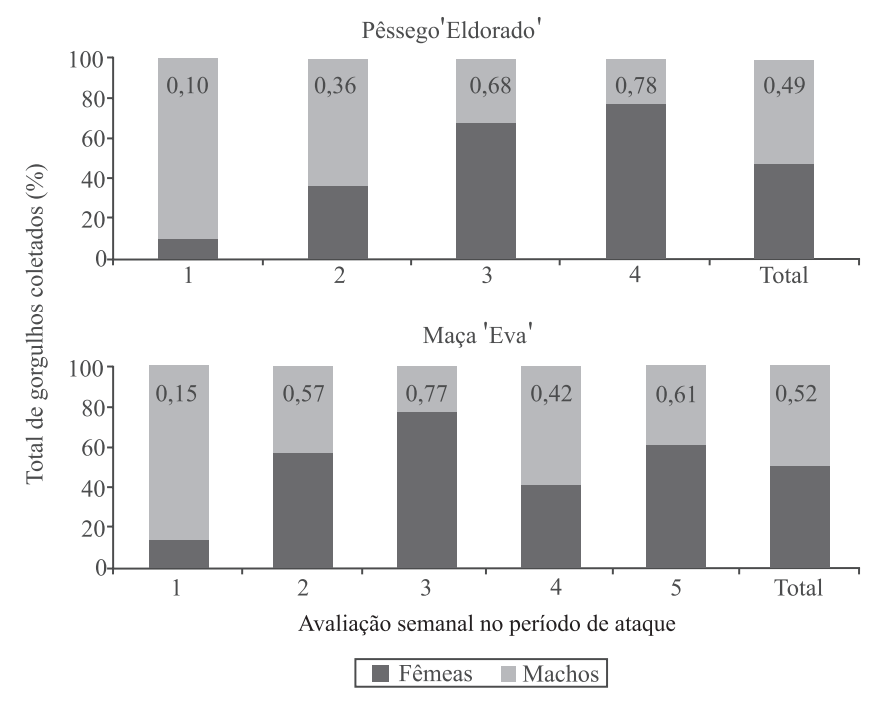

Figura 4. Percentagem total de gorgulhos, machos e fêmeas, e razão sexual de Sitophilus zeamais, capturados em armadilhas Pet-milho em pomar de pessegueiro, cultivar Eldorado, e de macieira, cultivar Eva. reconhecidamente eficientes na captura do gorgulho, o que dificulta o estabelecimento do monitoramento e controle.

\section{Conclusões}

1. Na região de Pelotas, Rio Grande do Sul, a ocorrência da espécie Sitophilus zeamais em pessegueiros se dá tanto em cultivares precoces como em tardias, com pico de ataque na fase de colheita.

2. Na cultura da macieira, o período de ataque da espécie $S$. zeamais é de sete semanas, enquanto em pessegueiro, é de três a quatro semanas.

3. O início da infestação de S. zeamais em pessegueiro e macieira se dá nos frutos do terço superior da planta, acima de $1,7 \mathrm{~m}$.

4. Os machos de $S$. zeamais são os primeiros a infestar os pomares de pessegueiro e macieira.

\section{Agradecimentos}

Ao Conselho Nacional de Desenvolvimento Científico e Tecnológico (CNPq) e ao Serviço Alemão de Intercâmbio Acadêmico (DAAD), pela concessão de bolsas e pelo apoio financeiro; e ao Professor Germano Henrique Rosado Neto, do Departamento de Zoologia da Universidade Federal do Paraná (UFPR), pela identificação dos insetos.

\section{Referências}

APPEL, H.M. Phenolics in ecological interactions: the importance of oxidation. Journal of Chemical Ecology, v.19, p.1521-1552, 1993. DOI: $10.1007 / \mathrm{BF} 00984895$.

ARIOLI, C.J.; BOTTON, M.; CARVALHO, G.A. Controle químico da Grapholita molesta (Busck) (Lepidoptera: Tortricidae) na cultura do pessegueiro. Ciência Rural, v.34, p.1695-1700, 2004. DOI: $10.1590 /$ S0103-84782004000600005.

BOTTON, M.; LORINI, I.; AFONSO, A.P.S. Ocorrência de Sitophilus zeamais Mots. (Coleoptera: Curculionidae) danificando a cultura da videira no Rio Grande do Sul. Neotropical Entomology, v.34, p.355-356, 2005a. DOI: 10.1590/ S1519-566X2005000200027.

BOTTON, M.; LORINI, I.; LOECK, A.E.; AFONSO, A.P.S. $\mathrm{O}$ gorgulho do milho Sitophilus zeamais (Coleoptera: Curculionidae) como praga em frutíferas de clima temperado. Bento Gonçalves: Embrapa Uva e Vinho, 2005b. (Embrapa Uva e Vinho. Circular técnica, 58).

BOUCHARD, P.; BOUSQUET, Y.; DAVIES, A.E.; ALONSO-ZARAZAGA, M.A.; LAWRENCE, J.F.; LYAL, C.H.C.; NEWTON, A.F.; REID, C.A.M.; SCHMITT, M.; ŚLIPIŃSKI, 
S.A.; SMITH, A.B.T. Family-group names in Coleoptera (Insecta). Zookeys, v.88, p.1-972, 2011. DOI: 10.3897/zookeys.88.807.

ELIAS, M.C.; OLIVEIRA, M. de; VANIER, N.L. (Ed.). Qualidade do arroz da pós-colheita ao consumo. Pelotas: UFPel, 2012. $626 \mathrm{p}$.

FACHINELLO, J.C.; PASA, M. da S.; SCHMITZ, J.D.; BETEMPS, D.L. Situação e perspectivas da fruticultura de clima temperado no Brasil. Revista Brasileira de Fruticultura, v.33, p.109-120, 2011. DOI: 10.1590/S0100-29452011000500014.

HÄRTER, W. da R.; GRÜTZMACHER, A.D.; NAVA, D.E.; GONÇALVES, R. da S.; BOTTON, M. Isca tóxica e disrupção sexual no controle da mosca-da-fruta sul-americana e da mariposa-oriental em pessegueiro. Pesquisa Agropecuária Brasileira, v.45, p.229-235, 2010. DOI: 10.1590/ S0100-204X2010000300001.

HICKEL, E.R.; SCHUCK, E. Infestação e danos do gorgulho-do-milho em videira. Agropecuária Catarinense, v.18, p.49-52, 2005.

HICKEL, E.R.; SCHUCK, E. Pet-milho: armadilha para o monitoramento do gorgulho-do-milho, Sitophilus zeamais (Coleoptera: Curculionidae), em parreirais. Agropecuária Catarinense, v.21, p.51-54, 2008.

LANDOLT, P.J.; PHILLIPS, T.W. Host plant influences on sex pheromone behavior of phytophagous insects. Annual Review of Entomology, v.42, p.371-391, 1997. DOI: 10.1146/annurev. ento.42.1.371.

LESKEY, T.C.; WRIGHT, S.E. Influence of host tree proximity on adult plum curculio (Coleoptera: Curculionidae) responses to monitoring traps. Environmental Entomology, v.33, p.389-396, 2004. DOI: $10.1603 / 0046-225 X-33.2 .389$.

LIKHAYO, P.W.; HODGES, R.J. Field monitoring Sitophilus zeamais and Sitophilus oryzae (Coleoptera: Curculionidae) using refuge and flight traps baited with synthetic pheromone and cracked wheat. Journal of Stored Products Research, v.36, p.341-353, 2000. DOI: 10.1016/S0022-474X(99)00052-1.

LIMA, C.A.B. de; GRÜTZMACHER, D.D.; KRÜGER, L.R.; GRÜTZMACHER, A.D. Diagnóstico da exposição ocupacional a agrotóxicos na principal região produtora de pêssego para a indústria do Brasil. Ciência Rural, v.39, p.900-903, 2009. DOI: 10.1590/S0103-84782008005000090.

MOREIRA, M.A.B.; ZARBIN, P.H.G.; CORACINI, M.D.A. Feromônios associados aos coleópteros-praga de produtos armazenados. Química Nova, v.28, p.472-477, 2005. DOI: 10.1590/S0100-40422005000300019.

NAVA, D.E.; BOTTON, M. Bioecologia e controle de Anastrepha fraterculus e Ceratitis capitata em pessegueiro. Pelotas: Embrapa Clima Temperado, 2010. 29p. (Embrapa Clima Temperado. Documentos, 315).

RASEIRA, M.C.B.; NAKASU, B.H. Peach breeding program in Southern Brazil. Acta Horticulturae, v.713, p.93-98, 2006.

SALLES, L.A.B. Do milho às frutas. Cultivar Hortaliças e Frutas, n.17, p.10-11, 2003.

SAS INSTITUTE. Getting started with the SAS learning edition. Cary: SAS Institute, 2002.

SILVA, S.J.P. da; KOHLS, V.K.; MANICA-BERTO, R.; RIGATTO, P.; ROMBALDI, C.V. Apropriação tecnológica da produção integrada de pêssegos na região de Pelotas no Estado do Rio Grande do Sul. Ciência Rural, v.41, p.1667-1673, 2011. DOI: 10.1590/S0103-84782011005000121.

TORALLES, R.T.; VENDRUSCULO, J.L.; MALGARIM, B.M.; CANTILHANO, R.F.; SHUNEMANN, A.P.P.; ANTUNES, P.L. Características físicas e químicas de cultivares brasileiras de pêssego em duas safras. Revista Brasileira de Agrociência, v.14, p.327-338, 2008.

UKEH, D.A.; BIRKETT, M.A.; BRUCE, T.J.; ALLAN, E.J.; PICKETT, J.A.; LUNTZ, A.J. Behavioural responses of the maize weevil, Sitophilus zeamais, to host (stored-grain) and non-host plant volatiles. Pest Management Science, v.66, p.44-50, 2010. DOI: $10.1002 /$ ps.1828.

VÁSQUEZ-CASTRO, J.A.; BAPTISTA, G.C.; TREVISAN, L.R.P.; GADANHA JUNIOR, C.D. Flight activity of Sitophilus oryzae (L) and Sitophilus zeamais Motsch. (Coleoptera: Curculionidae) and its relationship with susceptibility to insecticides. Neotropical Entomology, v.38, p.405-409, 2009. DOI: $10.1590 / \mathrm{S} 1519-566 X 2009000300017$.

Recebido em 19 de outubro de 2012 e aprovado em 26 de março de 2013

Pesq. agropec. bras., Brasília, v.48, n.4, p.358-364, abr. 2013

DOI: $10.1590 / \mathrm{S} 0100-204 X 2013000400002$ 